\title{
Rutting as a Function of Dynamic Modulus and Gradation
}

\author{
Alex K. Apeagyei, Ph.D., P.E., M.ASCE \\ Virginia Transportation Research Council, Charlottesville, VA, USA; email:alex.apeagyei@vdot.virginia.gov
}

\begin{abstract}
This study was conducted to investigate rutting resistance of asphalt concrete (AC) mixtures as a function of dynamic modulus and gradation. The Flow number (FN) test, the (NCHRP 9-19) recommended procedure for evaluating rutting resistance of AC mixtures, was used to simulate rutting in the laboratory. The FN test involves applying a repeated creep load to AC specimens for 10,000 cycles or until an accumulated strain of five percent. FN tests were conducted at $54^{\circ} \mathrm{C}$ and accumulated strain was monitored for each load cycle. The results were used to determine the onset of tertiary flow (or FN) for 16 AC mixtures (eight surface mixes, five base mixes, and three stone matrix asphalt) produced in Virginia. First-order multiple regression models were developed to describe the relationship among FN, dynamic modulus, and gradation. The results showed FN was strongly correlated to dynamic modulus values at $38^{\circ} \mathrm{C}$, and gradation (percent passing various sieve sizes) for the $16 \mathrm{AC}$ mixtures. Using previously published data, the veracity of the relationship of FN as a function of dynamic modulus and gradation was verified for 12 mixtures. The results suggest dynamic modulus and gradation could be considered as potential rutting specification parameters for QC/QA purposes in the field. The results may also be useful for optimizing the laboratory mix design process.
\end{abstract}

CE Database subject headings: Asphalts, Mixtures, Laboratory tests Author keywords: Dynamic modulus, gradation, rutting, flow number

\section{Introduction}

This study involved subjecting asphalt concrete (AC) mixtures to repeated creep load in the laboratory to determine the effects certain mixture properties such as dynamic modulus and gradation have on rutting resistance. Rutting was simulated using the flow number (FN) test. 
The FN test (AASHTO 2007) is very important to pavement designers as FN of a mixture could be used to aid in the characterization and selection of the best available materials for producing $\mathrm{AC}$ mixtures that are resistant to rutting. FN has shown good correlation with field rutting of AC mixtures for different traffic levels (Witczak 2007). FN has also been used to rank asphalt mixtures in terms of rutting susceptibility in both laboratory tests and field performance (Mohammad et al. 2006).

Rutting is believed to be affected by several AC properties in addition to temperature and loading effects. To minimize the potential for rutting certain key factors affecting rutting need to be identified so the design process could be optimized by modifying these important factors.

Kaloush (2001) showed that rutting is affected by mixture volumetric properties (including effective asphalt content and air voids), binder viscosity, and testing temperature. Kvasnak et al. (2007) identified several asphalt mixture properties that affect rutting (measured by FN) to include binder grade, binder viscosity, asphalt content, testing temperature, nominal maximum aggregate size, voids in the mineral aggregate, percentage passing sieves (No.4, No.16, No.200), and number of gyrations.

Rodezno et al. (2010) identified 12 parameters that affect rutting of asphalt mixtures in the laboratory to include maximum shear stress, normal stress, testing temperature, binder viscosity, aggregate gradation (percent retained on 3/4-in, 3/8-in and No. 4 sieves), air voids, binder content, effective binder content, voids in the mineral aggregate, and voids filled with asphalt. Models for predicting FN were developed in these studies based on the aforementioned list of factors.

Another parameter that has been suggested as affecting rutting is dynamic modulus. However there are no consensus regarding the effect of dynamic modulus on rutting (Birgisson and Roque 2004; Zhou and Scullion 2007; Witczak et al. 2002; and Pellinen and Witczak 2002). Possible reasons for the observed lack of consensus might be because reported testing conditions at which dynamic modulus for rutting evaluation are selected varies among various investigators. Suggested ranges of testing frequencies for evaluating dynamic modulus for rutting varies widely and was reported to range from 0.02 to $20 \mathrm{~Hz}$ by Ekingen (2004). Shenoy and Romero (2002) suggested an approach to select a normalizing frequency parameter corresponding to a reference dynamic modulus of $4 \mathrm{MPa}$ to evaluate rutting in laboratory test specimens. 
Witczak et al. (2002) and Pellinen and Witczak (2002) reported good correlation between dynamic modulus and rutting. Dynamic modulus obtained from unconfined compression tests at $54{ }^{\circ} \mathrm{C}$ and a $\mathrm{t}$ a frequency of $5 \mathrm{~Hz}$ was considered a good indicator of rutting based on the repeated load FN test. Other studies have reported little to no correlation between dynamic modulus and rutting measured with the asphalt pavement analyzer (APA). Ullidtz (1987) found no good correlation between APA rut depth and dynamic modulus measured at $40^{\circ} \mathrm{C}$ and $1 \mathrm{~Hz}$ frequency as did Ekingen (2004) who compared dynamic modulus obtained at $1 \mathrm{~Hz}$ and $4 \mathrm{~Hz}$ and APA results. Mohammad et al. (2006) compared dynamic modulus measured at $54^{\circ} \mathrm{C}$ and $5 \mathrm{~Hz}$ loading frequency with rutting and reported that dynamic modulus could not differentiate between rutting susceptibility of the mixtures tested.

In most of the aforementioned studies, the effect of gradation was not explicitly evaluated in conjunction with dynamic modulus which may help explain some of discrepancies observed in the reported relationship between dynamic modulus and rutting. Thus additional studies involving the evaluation of factors influencing rutting is still needed. Results of such studies may also be important in other areas as discussed next.

The enormous list of factors identified as affecting rutting illustrates the difficulty one may encounter when attempting to optimize a given asphalt mixture for resistance against rutting. A close inspection of the factors affecting rutting identified in previous studies suggests these factors could be classified into two groups. First is the binder property controlling the viscoelastic and viscoplastic behavior, and second are aggregate properties including gradation that controls the elastic (and possibly plastic) behavior of the mix. Also because of the viscoelastic nature of asphalt mixture response to load, selection of a suitable dynamic modulus value (at a given testing temperature and frequency) for evaluating rutting remains a challenge to be solved. It is anticipated in this study that dynamic modulus and certain key gradation parameters could be used as surrogates for the numerous factors identified in previous studies to affect rutting of asphalt mixtures. By using only a few relevant material properties, it is hoped that the approach proposed in this study could lead to a more efficient and rational means of evaluating rutting during a routine mix design process. Prediction models utilizing the combined effects of dynamic modulus and certain gradation parameters will be developed to estimate $\mathrm{FN}$ of AC mixtures in the laboratory. 


\section{Purpose and Scope}

Numerous factors have been identified in past studies to account for the rutting behavior of asphalt mixtures. Because of the rather large number of identified factors, applying this knowledge to routine mix design could be quite difficult since a designer will have to control up to 15 or more different factors in order to produce a rut-resistance mix. If the number of factors affecting rutting could be narrowed down to a few important ones, a routine mix design process could be optimized. It is therefore important that a relationship between FN and key gradation and stiffness parameters which are known to affect rutting be established so that the prediction of rutting could be improved.

The main objective of this paper was to investigate rutting resistance of $\mathrm{AC}$ mixtures as a function of dynamic modulus and gradation and develop a mathematical relationship between them. The scope of the study was limited to 16 AC mixes including: eight dense-graded surface mixes of nominal maximum aggregate size (NMAS) of $9.5 \mathrm{~mm}$ and $12.5 \mathrm{~mm}$; five dense-graded base mixes with an NMAS of $25.0 \mathrm{~mm}$; and three stone asphalt matrix with an NMAS of $12.5 \mathrm{~mm}$. All the tested specimens were produced according to Virginia specifications using plant-mixed laboratory-compacted asphalt mixtures. Predictive models relating FN to dynamic modulus and gradation were developed based on the 16 mixtures considered. The strong dependence of FN on dynamic modulus and gradation observed in the 16 mixtures was verified using published data on 12 different mixtures.

\section{Methodology}

Sixteen AC mixtures consisting of 13 dense-graded mixtures and three stone matrix asphalt (SMA) were tested using the dynamic modulus and FN tests. The mixtures were selected to be as representative as possible of the commonly used AC mixtures in Virginia. The mixtures contained RAP amounts ranging from 0 to $25 \%$ by weight. Three different binder types were used (PG 64-22 for mixes with A designation; PG 70-22 for mixes with D designation; and PG 76-22 for mixes with E designation and containing polymer modified-asphalt). Mixes A, D, and E are designed for pavements carrying up to 3 million ESALs, 3-10 million ESAL and > 10 million ESAL, respectively (VDOT, 2006).

\section{Materials Sampling and Collection}


As stated above, samples of the most commonly used mixture types were collected from around the Commonwealth of Virginia. Majority of the mixes sampled were surface mix (SM) followed by base mix (BM), and SMA mixes.

Details of the mixtures sampled including the asphalt binder grade, amount of RAP, and mixture source are shown in Table 1. All samples were plant-mixed and were sampled loose at the project site and sent to laboratory for further processing and testing. Samples were stored in a temperature controlled environment in sealed containers before testing. Additional details about the mixtures including key gradation parameters and mixture volumetrics are shown in Table 2 and Table 3, respectively. The loose mixtures were processed into compacted specimens for mechanical testing as detailed in subsequent sections under laboratory testing. The main mechanical laboratory tests conducted included dynamic modulus and flow tests using an asphalt material performance tester (AMPT).

\section{Laboratory Compaction Methods}

A Superpave gyratory compactor was used to fabricate specimens used for the dynamic modulus and the FN tests. The mixtures for the various tests were compacted to a target air void level of $7 \pm 0.5 \%$. This was accomplished by determining the compaction height needed to obtain the required target air void content. It was determined that the base mixes (NMAS $25.0 \mathrm{~mm}$ ) required to be compacted to a height of $200 \mathrm{~mm}$ while the SM and SMA mixes (9.5 $\mathrm{mm}$ and $12.5 \mathrm{~mm}$ NMAS) required to be compacted to height of 175 $\mathrm{mm}$. Next a coring rig was used to obtain the required $150 \mathrm{~mm}$ tall by $100 \mathrm{~mm}$ diameter specimen from the gyratory compacted specimen for testing. The same specimens were used for both the dynamic modulus and the FN test since the former is considered a non-destructive test.

\section{Dynamic Modulus Tests}

Dynamic modulus tests were performed with an IPC AMPT according to AASHTO TP62. Tests were performed on $100 \mathrm{~mm}$ diameter by $150 \mathrm{~mm}$ tall specimens in the uniaxial compressive mode. Tests were conducted at 5 temperatures ranging from $-10^{\circ} \mathrm{C}$ to $54^{\circ} \mathrm{C}$ and six loading frequencies ranging from $0.1 \mathrm{~Hz}$ to $25 \mathrm{~Hz}$. To insure against damage to the test samples, the tests were conducted starting from the coldest to the warmest temperature. In addition, at each testing temperature, the tests were performed starting 
from the highest to the lowest frequency. Load levels were selected in such a way that at each temperature-frequency combination, applied strain was in the range of 75-125 micro-strain. This was done to ensure that testing was conducted in the linear viscoelastic range of the $\mathrm{AC}$ mixes, a necessary requirement for a valid dynamic modulus test. Stress versus strain values were captured continuously and used to calculate dynamic modulus values. Dynamic modulus was computed automatically by the test software. Results at each temperature-frequency combination for each mixture type are reported for three replicate specimens.

\section{FN tests}

The FN tests were performed on $100 \mathrm{~mm}$ diameter by $150 \mathrm{~mm}$ tall specimens using NCHRP Project 9-19 procedures. An IPC UPM AMPT with 25-kN load cell was used. Tests were performed on specimens that were previously used for the dynamic modulus tests. The FN tests involved subjecting a specimen of asphalt concrete specimens to a repeated haversine axial compressive load pulse of $0.1 \mathrm{sec}$ every $1.0 \mathrm{sec}$. The test is conducted at a temperature that represents the expected pavement temperature at the site and layer of the pavement section. In this study the $\mathrm{FN}$ test was conducted at $54^{\circ} \mathrm{C}$ which represents the $50 \%$ reliability maximum high pavement temperature as determined using the LTPPBind software (Pavement Systems 2005) for locations in the southeastern portion of the US. The FN tests were all performed in the unconfined mode using a deviatioric stress of $206 \mathrm{kPa}$. The tests were continued to 10,000 cycles or a permanent strain of five percent whichever came first.

\section{Results and Discussion}

In this section, the effects of dynamic modulus and gradation on rutting are evaluated. First dynamic modulus data at five temperatures and six testing frequencies for each of the 16 mixtures are presented. A mastercurve consisting of dynamic modulus values was developed for each mixture and plotted to illustrate the temperature and frequency dependency of the asphalt mixtures and how it may complicate the choice of a dynamic modulus value to use for evaluating rutting. Next the results of the FN tests are presented with an illustration of how the FN is determined numerically using standard AASHTO TP62 procedures. Finally predictive equations relating FN to dynamic modulus and gradation parameters are 
presented and discussed. The sections concludes with an attempt to verify the models developed for predicting $\mathrm{FN}$ as a function of dynamic modulus and gradation, using 12 mixtures from previously published research.

\section{Dynamic Modulus Tests}

Results for the sixteen different asphalt mixtures tested in uniaxial compression mode at five temperatures $\left(-10^{\circ} \mathrm{C}, 4^{\circ} \mathrm{C}, 20^{\circ} \mathrm{C}, 38^{\circ} \mathrm{C}\right.$, and $\left.54^{\circ} \mathrm{C}\right)$ and six frequencies $(25 \mathrm{~Hz}, 10 \mathrm{~Hz}, 5 \mathrm{~Hz}, 1 \mathrm{~Hz}, 0.5 \mathrm{~Hz}$, and $0.1 \mathrm{~Hz})$ are shown in Figures 1 through 3. The results are grouped according to the type of the mixture (SM, BM, SMA) as defined above.

The mean dynamic modulus data for each mixture type show a decreasing trend with an increase in temperature. The trend is reversed when considering frequency as dynamic modulus values increased with increasing frequency. The change in dynamic modulus with temperature is however not consistent among the various mixtures. For example in Figure 1 specimen $08-1045 \mathrm{D}$ is ranked the highest in terms of stiffness among the surface mixes at each testing temperature. This is not the case for the SMAs as specimen $08-1025 \mathrm{E}$ which was ranked the stiffest at the coldest temperature ended as the softest ranked mixtures at the higher testing temperatures which might be due to polymer modification as all mixtures with the "E" designation are required to contain polymer-modified asphalt binder. This is an example of difficulty one may encounter if the evaluation of rutting is based solely on dynamic modulus measurements.

For all the mixtures, the amount of RAP appears to have a significant effect on dynamic modulus values in both expected and unexpected ways. The clearest example of the positive effect of RAP on rutting can be seen in the surface mixes where the stiffest surface mix at the highest temperature for the surface mixes was $08-1045 \mathrm{D}$ which also contained the highest (20\%) RAP amount for this class of mixture. The trend is confounded in the BM and SMA mixes probably due to the effect of the different binder grades (polymer-modified) used in these mixtures. The foregoing analysis which shows different temperature susceptibility in the various mixes suggest the need to combine the effect of temperature and loading rate in a more formal way. The combined effects of temperature and frequency on dynamic modulus was characterized by constructing master curves using the concept of the time-temperature 
superposition principle. The time-temperature superposition principle simply implies test data obtained at low temperatures is equivalent to data obtained at high frequencies and vice versa.

The data at the five testing temperatures and six testing frequencies for each mix were combined to construct dynamic modulus master curves. A sigmoidal model (Equation 1) was used to describe the mastercurves at a reference temperature of $20^{\circ} \mathrm{C}$. A non-linear analysis was performed using a commercially available optimization routine (Microsoft Excel Solver) to obtain the model parameters of the master curve by minimizing the sum of squares of error between the predicted and the measured dynamic modulus values. Dynamic modulus mastercurves for the mixtures are shown in Figures 1 through 3 plotted on a semi-log scale.

There are several reasons for constructing dynamic modulus master curves for asphalt mixtures in this study. First a master curve of dynamic modulus provides the ability to predict dynamic modulus at temperatures and /or frequencies which will be difficult or impossible to determine in the laboratory due to equipment limitations or time constraints. Another advantage of a master curve relates to the ability to model pavements across all possible pavement climatic and loading conditions. A master curve is also useful for ranking mixture performance. For instance in Figures 1 through 3, mixtures with higher dynamic modulus at lower (reduced) frequencies (equivalent to high test temperatures) would be expected to exhibit better rutting potential than mixtures with lower dynamic modulus values. Similarly mixtures having low stiffness at high reduced frequencies (equivalent to low temperatures) are expected to be more resistant to low temperature cracking. As would be shown below, mixtures such as 09-1049A which plotted lowest at low reduced frequency also showed low FN values. However it should be noted this observation is too simplistic as some of the plots cross each other and therefore the magnitude of dynamic modulus values alone may not be enough for ranking rutting performance. This was a major motivation of this study.

The type of aggregate structure (dense-graded vs. gap-graded) appears to be related to the level of stiffness of the mix. Gap-graded SMA mixes tested in this study appeared to be softer than the densegraded mixes as the three most softest mixes were all SMA mixes. It should be noted that all the SMA mixes were either " $D$ " or "E" suggesting mixes which likely used polymer-modified asphalt binders. It is also interesting to note the effect of RAP on SMA stiffness; of the three SMA mixes, the stiffest (08- 
1025E) contained $10 \%$ RAP while the other two had no RAP. Another observation was that the SMA mixes appear to be significantly softer at low temperatures but of comparable stiffness to most of the dense-graded mixes at high test temperatures.

$$
\log \left(E^{*}\right)=\delta+\frac{\alpha}{1+e^{\left(\beta+\gamma\left(\log f_{r}\right)\right)}}
$$

where

$\mathrm{f}_{\mathrm{r}}=$ loading frequency at the reference temperature,

$\delta=$ minimum value of dynamic modulus,

$\delta+\alpha=$ maximum value of dynamic modulus, and

$\beta, \gamma=$ parameter describing the shape of the sigmoidal function.

\section{FN Tests Results}

Results of flow number tests performed at $54^{\circ} \mathrm{C}$ are presented in this section. During the test, axial strain and cumulative number of load cycles were monitored continuously by the FN test software. From the results, plots of rate of change of strain with number of cycles could be constructed. Figure 4 is a typical plot of accumulated strain versus number of loading cycles obtained for the mixtures.

Three stages are typically identified from the plot of permanent strain versus loading cycle. These three stages have been classified as primary, secondary and tertiary (Witczak and Sullivan 2002). The primary flow is characterized by a decrease in the strain rate with time. The secondary flow phase is characterized by a relatively constant strain rate. The tertiary flow follows the secondary phase and begins when the strain rate begins to increase. At the tertiary stage, the specimen undergoes significant deformation with individual aggregates within the aggregate skeleton moving past each other (Kanitpong and Bahia 2005 and Little et al. 1993). FN is the cycle number at the initiation of tertiary flow (Witczak 2007).

The FN is determined mathematically as the cycle number at which the strain rate is a minimum. For this study, the Francken model (Biligiri et al. 2007) as implemented in the AMPT software and shown 
in Equations 2 and 3 were used estimate the FN. FN is defined as the point where Equation 3 changes from negative to positive.

Table 4 shows summarized results of flow number tests results obtained for each mix. The results represent average FN for three replicate specimens for each mixture type. Also shown in Table 4 are the variability in test results represented by the coefficient of variation (COV) which ranged from 1.9 to 38.0 percent. This level of variability are within previously reported ranges by investigators. For the mixtures considered, FN ranged from about 600 to about 8400 . In general the stiffer mixes with high dynamic modulus values appear to exhibit higher FN which is to be expected.

The dense-graded mixes (BM and SM) exhibited relatively high rutting resistance compared with the SMA as evidenced by the higher FN values. However most of SMA mixtures sustained almost double the accumulated strain at FN compared to the dense-graded mixes. The average FN values for the densegraded mixtures were 5211 and 1379 for mixtures containing PG 70-22 (D mixes) and PG 64-22 (A mixes) binders, respectively. It must also be noted that all $\mathrm{D}$ mixes contained between 10 to 20 percent RAP while the RAP amount for the A mixes ranged from 0 to $25 \%$. The effect of RAP in these mixtures appear to be an increase in FN. For the dense-graded mixtures there appears to be no statistically significant difference between SM and BM mixes ( $\mathrm{p}$-value $=0.357)$. The major distinction between the $\mathrm{SM}$ and $\mathrm{BM}$ is the nominal maximum aggregate size (NMAS). The fact that FN is not significantly different irrespective of NMAS suggest, the parameter may not be an important factor in rutting for the mixtures considered in this study. In other words, NMAS is may not be a good indicator of rutting resistance of AC considered in this study.

$$
\begin{gathered}
\left.\varepsilon_{p}(N)\right)=A N^{B}+C\left(e^{D N}-1\right) \\
\frac{\partial^{2} \varepsilon_{p}}{\partial N^{2}}=A * B *(B-1) * N^{B-2}+C * D^{2} * e^{D N}
\end{gathered}
$$

where:

$$
\varepsilon_{p}=\text { Permanent strain from the flow number test, }
$$




$$
\mathrm{N}=\text { number of loading cycles, }
$$

$\mathrm{A}, \mathrm{B}, \mathrm{C}$, and $\mathrm{D}=$ regression constants, and

$\frac{\partial^{2} \varepsilon_{p}}{\partial N^{2}}=$ second derivative of permanent strain versus $\mathrm{N}$.

\section{Rutting as a Function of Dynamic Modulus and Gradation}

It is a generally accepted fact that rutting of asphalt mixtures is affected by both stiffness and gradation. However the effects of stiffness as measured by dynamic modulus and gradation are not commonly evaluated together. The coupled effects of dynamic modulus and gradation has not received much attention in the published research. In order to determine if a relationship exits between dynamic modulus and gradation on the one hand and rutting (measured by FN), an analysis was conducted on the results of the 16 different asphalt mixtures that were evaluated in this study.

Multiple linear regression analyses were conducted to determine promising models for predicting FN as a function of dynamic modulus and gradations for each mix type using a commercially available statistical analysis software (SAS, 2007). A significance level of 0.05 was assumed for all the statistical analyses. As mentioned previously, dynamic modulus testing was conducted at five testing temperatures and six loading frequencies. The challenge was to find which temperature-frequency combination yielded dynamic modulus values most correlated with rutting. In addition, gradation parameters (percent passing various sieves) as well as key volumetric properties (percent air voids, effective asphalt content, voids in mineral aggregates, etc) were used for developing the models. To accomplish this objective, several statistical analyses involving dynamic modulus values at five loading frequencies and testing temperature of $38^{\circ} \mathrm{C}$ was conducted. The testing temperature of $38^{\circ} \mathrm{C}$ was chosen because it is close to the effective temperature for permanent deformation (El-Basyouny and Jeong, 2009). Criteria for selecting the most promising model was based on several key statistics including $\mathrm{R}^{2}$, Mallows' $\mathrm{Cp}$, and MSE. The model with the lowest $\mathrm{Cp}$ value approximately equal to the number of model parameters for all possible combinations of model variables was considered the most adequate. The selected model had a high $\mathrm{R}^{2}$ $(=0.91)$, the lowest $\mathrm{Cp}(=9.8)$ and the lowest MSE. The p-value for the model was less than 0.0001 as 
indicated in Table 5. The Cp value of 9.8 was less than the number of variables in the model suggesting a possible high predictive ability.

The result of the statistical analyses showing predicted model parameters and key statistics for the most promising model is summarized in Table 5. The analyses showed (as indicated by p-values less than 0.05) that dynamic modulus values obtained at $38^{\circ} \mathrm{C}$ and loading frequencies $10.0,1.0$, and $0.1 \mathrm{~Hz}$ showed some potential as predictive parameters for FN. Also key gradation parameters (percent passing various sieve sizes) showed significant effect on FN. Mixture volumetrics including air void and voids in mineral aggregate (VMA) were also found to be significant factors. These gradation parameters as well as the dynamic modulus obtained at $38^{\circ} \mathrm{C}$, were selected to develop model parameters for the functional form shown in Equation 4.

Equation 4 could be considered a first-order multiple regression model. For such models one could attach some meaning to the various $\beta$-parameters. The parameter $\beta_{0}$ is the $y$-intercept and represents the expected value of FN when dynamic modulus and the gradation parameters are all zero. Obviously $\beta_{0}$ could only be used for prediction purposes in this study and not for interpretation since neither dynamic modulus nor the gradation parameters in Equation 4 could be zero for $\mathrm{AC}$ mixtures. The remaining $\beta$ parameters ( $\beta_{1}$ through $\left.\beta_{10}\right)$ are the so called partial slopes. Each $\beta_{\mathrm{i}}(\mathrm{i}=1$ to 10$)$ represents a unit change in FN for a unit increase in one of the variables when all other variables are held constant. Thus it could be hypothesized that if the effects of these parameters are additive, FN could be influenced (increase or decrease) by varying dynamic modulus and gradation parameters. Additional studies are required to verify this.

Figure 5 compares the measured FN and the predicted FN using Equation 4 for the model parameters detailed on Table 5. It can be seen from Figure 5 that the models predicted FN of the mixtures quite well for the mixtures considered in this study. The results show that FN could be considered as a function of dynamic modulus and certain gradation parameters with some level of certainty $(\alpha=0.05)$ for the mixtures considered in this study. The functional form of the model (Equation 4) is potentially important as it could allow FN to be computed knowing only dynamic modulus and readily available gradation parameters. Thus during the mix design process, several different mixtures could be evaluated 
for rutting without the need to perform the time-consuming FN tests. FN tests could then be limited to the most promising mix design. The equation may also be quite useful during mix design process as the parameters such as dynamic modulus and gradation could be quantitatively varied to produce rut-resistant mixes. The models could also be used as a basis for using dynamic modulus and gradation as a quality control / quality assurance (QC/QA) tool.

$$
F N=\beta_{0}+\sum_{i=1}^{10} \beta_{i} \chi_{i}
$$

where:

$$
\begin{aligned}
& \mathrm{FN}=\text { flow number at } 54.4^{\circ} \mathrm{C}, \\
& \chi_{1}=\text { percent air voids }, \\
& \chi_{2}=\text { percent passing } 19.0 \mathrm{~mm} \text { sieve, } \\
& \chi_{3}=\text { percent passing } 12.5 \mathrm{~mm} \text { sieve, } \\
& \chi_{4}=\text { percent passing } 9.5 \mathrm{~mm} \text { sieve, } \\
& \chi_{5}=\text { percent passing } 4.75 \mathrm{~mm} \text { sieve, } \\
& \chi_{6}=\text { percent passing } 2.36 \mathrm{~mm} \text { sieve, } \\
& \chi_{7}=\text { dynamic modulus at } 38^{\circ} \mathrm{C} \text { and } 10 \mathrm{~Hz} \text { in } \mathrm{MPa}, \\
& \chi_{8}=\text { dynamic modulus at } 38^{\circ} \mathrm{C} \text { and } 1 \mathrm{~Hz} \text { in } \mathrm{MPa}, \\
& \chi_{9}=\text { dynamic modulus at } 38^{\circ} \mathrm{C} \text { and } 0.1 \mathrm{~Hz} \text { in } \mathrm{MPa}, \\
& \chi_{10}=\text { percent voids in mineral aggregate }(\mathrm{VMA}), \text { and } \\
& \beta_{i}=\text { regression parameters } .
\end{aligned}
$$

\section{Verification of FN as Function of Dynamic Modulus and Gradation}

The preceding results and discussions suggest some evidence of FN as a function of dynamic modulus and gradation for $16 \mathrm{AC}$ mixtures exists. The veracity of the relationship relating FN to dynamic modulus and gradation obtained in the current study was investigated using data from two previously published 
research studies (Cooper 2008, Mohammad et al. 2006) on 12 mixtures from Louisiana. These data were chosen because the testing conditions used in both studies are comparable to that used in the current study. Specifically the FN was obtained at $54^{\circ} \mathrm{C}$ using a deviator stress of $207 \mathrm{kPa}$ under unconfined conditions in both of the aforementioned studies. Dynamic modulus data at $38^{\circ} \mathrm{C}$ as well as mixture volumetric properties were also available from the above-mentioned references. Six AC mixtures of a similar binder grade but different gradations were selected from Mohammad et al. (2006) while the six mixtures reported on by Cooper (2008) containing crumb rubber-modified asphalt form the remainder. Pertinent details of the mix properties used are shown in Table 6.

Figure 6 shows the comparison of measured FN (from Mohammad et al. 2006 and Cooper 2008) and predicted FN (using the approach developed in current study). The observed correlation between predicted and measured FN was quite good $\left(\mathrm{R}^{2}=0.84\right)$ as shown in Figure 6. Given the rather high variability reported by Mohammad et al. and the fact that rubber modified binders were used by Cooper), the correlation between measured FN and predicted FN shown in Figure 6 appears to show some evidence of the veracity of the relationship developed in this study for describing FN as a function of dynamic modulus and gradation.

The results show a promising approach for estimating FN and hence rutting in $\mathrm{AC}$ mixtures using fundamental mixture properties such as dynamic modulus and gradation. Further study aimed at utilizing the rather strong correlation of FN to dynamic modulus and gradation observed in this paper for use during routine mix design and QC/QA purposes is recommended as very limited mixtures were considered in this study. Given the number of variables (10) used in the models presented in this study, a study involving a larger number of mixtures should be used to validate the models.

\section{Summary and Conclusions}

This study was conducted to investigate rutting resistance of $\mathrm{AC}$ mixtures as a function of dynamic modulus and gradation. $\mathrm{FN}$ tests conducted at $54^{\circ} \mathrm{C}$ were used to simulate rutting in $16 \mathrm{AC}$ mixtures in the laboratory. 
- FN was affected by RAP amount, binder type, and mixture type. FN for dense-graded mixtures (SM and $\mathrm{BM}$ ) was in general higher than for comparable SMA mixtures. It must however be noted that a very limited number of SMA mixtures were tested in this study.

- A model of FN as a function of dynamic modulus and gradation developed during this study was found to have good predictive value as indicated by the low $\mathrm{Cp}$, and high $\mathrm{R}^{2}$ obtained from statistical analyses .

- The high predictive ability of the models developed in this study relating dynamic modulus and gradation to FN suggests these two mixture properties should be considered as potential specification parameters for the mix design process as well as field QC/QA activities. The possibility of predicting rutting resistance of asphalt mixtures from dynamic modulus and gradation has many potential practical implications and requires further investigation.

\section{Acknowledgements}

The authors acknowledges assistance of the following Virginia Transportation Research Council personnel to this study: Donnie Dodds and Troy Deeds for material testing.

\section{References}

American Association of State Highway and Transportation Officials (AASHTO). (2007). "AASHTO TP 62 standard method of test for determining dynamic modulus of hot-mix asphalt (HMA)." American Association of State Highway and Transportation Officials. Washington, D.C.

Biligiri, K. P., Kaloush, K. E., Mamlouk, M. S., and Witczak, M. W. (2007). "Rational modeling of tertiary flow for asphalt mixtures." Transportation Research Record: Journal of the Transportation Research Board, Transportation Research Board of the National Academies, No. 2001, 63-72, Washington, D.C.

Birgisson, B., and Roque, R., Kim, J., Pham, L.V. (2004). "The use of complex modulus to characterize the performance of asphalt mixtures and pavements in Florida." Final Report, Report No. 49104504-784-12, pg. 298, Florida Department of Transportation, Tallahassee, FL. 
Birgisson, B., and Roque, R. (2005). "Evaluation of the gradation effect on the dynamic modulus." Transportation Research Record: Journal of the Transportation Research Board, Transportation Research Board of the National Academies, No.1929, 193-199, Washington, D.C.

Cooper, S. B. (2008). "Characterization of HMA mixtures containing high recycled asphalt pavement content with crumb rubber additives.” PhD Thesis, Louisiana State University, Baton Rouge, Louisiana.

Ekingen, E.R. (2004). "Determining gradation and creep effects in mixtures using the complex modulus test.” M.S. Thesis, University of Florida, Gainsville, FL.

El-Basyouny, M.M., and Jeong, M.G. (2009). "Effective Temperature for Analysis of Permanent Deformation and Fatigue Distress on Asphalt Mixtures" Transportation Research Record: Journal of the Transportation Research Board, Transportation Research Board of the National Academies, No.2127, 155-163, Washington, D.C

Kanitpong, K., and Bahia, H. (2005). "Relating adhesion and cohesion of asphalts to the effect of moisture on laboratory performance of asphalt mixtures." Transportation Research Record: Journal of the Transportation Research Board, Transportation Research Board of the National Academies, No. 1901, 33-43.

Kvasnak, A., Robinette, C. J., and Williams, R. C. (2007). "Statistical development of a flow number predictive equation for the mechanistic-empirical pavement design guide.” TRB 86th Annual Meeting Compendium of Papers CD-ROM , Paper \#07-1000, 18p, Transportation Research Board.

Pavement Systems. (2005). “LTPPBIND. , v. 3.1 beta.” Pavement Systems, LLC, Bethesda, Md., 2005.

Mohammad, L.N., Wu, Z., Obularreddy, S., Cooper, S., and Abadie, C. (2006). "Permanent deformation analysis of hot-mix asphalt mixtures with simple performance tests and 2002 mechanisticempirical pavement design software." Transportation Research Record: Journal of the Transportation Research Board, Transportation Research Board of the National Academies, No. 1970, pp. 133-142.

Pellinen, T. K., and Witczak M. W. (2002). "Use of stiffness of hot-mix asphalt as a simple performance test." Transportation Research Board TRB 2002 Annual Meeting, Washington, D.C. 
SAS Institute Inc. SAS, Version 9.1.3. Cary, N.C., 2007.

Shenoy, A., and P. Romero. (2002). "Standardized procedure for analysis of dynamic modulus $\left|E^{*}\right|$ data to predict asphalt pavement distresses. Transportation Research Record: Journal of the Transportation Research Board, Transportation Research Board of the National Academies, No. 1789, pp. 173-182.

Witczak, M. W. (2007). "Specification criteria for simple performance tests for rutting." National Cooperative Highway Research Program, Report No. NCHRP Report 580, Washington, D.C.

Witczak, M. W., and Sullivan, B. (2002). "Superpave support and performance models management." National Cooperative Highway Research Program, 465.

Witczack M.W, Kaloush K, Pellinen T., El-Basyouny M., Quintus H.V. (2002). “Simple Performance Test for Superpave Mix Design.” NCHRP Report 465, National Cooperative Highway Research Program, pp.6.

Zhou, F., and Scullion, T. (2007). "Preliminary field validation of simple performance tests for permanent deformation: case study." Transportation Research Record: Journal of the Transportation Research Board, Transportation Research Board of the National Academies, No. 1832/2003, 209-216 
Table 1. Plant-mixed loose asphalt mixtures sampled for testing

\begin{tabular}{lllll}
\hline Mix type & Mix ID & $\%$ RAP & Binder grade & District \\
\hline Surface mixes & $08-1019 \mathrm{D}$ & 15 & PG 70-22 & Culpeper \\
& 08-1043A & 0 & PG 64-22 & NOVA \\
08-1045D & 20 & PG 70-22 & NOVA \\
08-1047D & 10 & PG 70-22 & Hampton Road \\
08-1036D & 10 & PG 70-22 & Staunton \\
& 08-1052E & 12 & PG 76-22 & Hampton Road \\
& $08-1055 \mathrm{D}$ & 25 & PG 70-22 & Lynchburg \\
& $09-1001 \mathrm{E}$ & 15 & PG 76-22 & Fredericksburg \\
Base mixes & $08-1044 \mathrm{~A}$ & 20 & PG 64-22 & NOVA \\
& $09-1049 \mathrm{~A}$ & 15 & PG 64-22 & Bristol \\
& $09-1051 \mathrm{D}$ & 15 & PG 70-22 & Bristol \\
& $09-1053 \mathrm{D}$ & 15 & PG 70-22 & Bristol \\
Stone matrix asphalt mixes & $09-1056 \mathrm{~A}$ & 25 & PG 64-22 & Richmond \\
& $08-1012 \mathrm{E}$ & 0 & PG 76-22 & Fredericksburg \\
& $08-1025 \mathrm{E}$ & 10 & PG 76-22 & Fredericksburg \\
& $08-1046 \mathrm{D}$ & 0 & PG 70-22 & Hampton Road \\
\hline
\end{tabular}


Table 2. Mixture gradation parameters

\begin{tabular}{llllllllllll}
\hline Mix ID & \multicolumn{1}{c}{ Sieve size $(\mathrm{mm})$} \\
\cline { 2 - 11 } & 25 & 19 & 12.5 & 9.5 & 4.75 & 2.36 & 1.18 & 0.6 & 0.3 & 0.15 & 0.075 \\
\hline 08-1019D & 100 & 100 & 99.9 & 97.2 & 60.5 & 40.6 & 29.0 & 19.6 & 12.1 & 8.4 & 5.8 \\
08-1043A & 100 & 100 & 98.8 & 91.9 & 58.3 & 41.9 & 30.1 & 20.4 & 13.0 & 8.7 & 5.8 \\
08-1045D & 100 & 100 & 99.8 & 91.8 & 40.5 & 24.4 & 18.3 & 14.0 & 9.8 & 6.4 & 4.2 \\
08-1047D & 100 & 100 & 100.0 & 95.3 & 66.6 & 47.9 & 37.8 & 27.5 & 16.0 & 9.6 & 6.6 \\
08-1036D & 100 & 100 & 96.8 & 84.2 & 51.6 & 33.2 & 25.4 & 20.8 & 13.5 & 7.9 & 5.6 \\
08-1052E & 100 & 100 & 96.6 & 86.1 & 61.1 & 37.7 & 23.1 & 15.1 & 10.6 & 8.2 & 6.8 \\
08-1055D & 100 & 100 & 96.5 & 84.7 & 50.2 & 42.5 & 35.0 & 24.1 & 12.3 & 7.7 & 5.2 \\
09-1001E & 100 & 100 & 94.6 & 83.2 & 57.6 & 39.8 & 29.2 & 20.0 & 11.4 & 6.9 & 4.6 \\
08-1044A & 99 & 91.2 & 56.3 & 42.0 & 28.7 & 22.9 & 19.0 & 14.6 & 9.7 & 6.4 & 4.4 \\
09-1049A & 98.5 & 91.8 & 74.2 & 64.1 & 39.8 & 24.6 & 16.8 & 12.9 & 10.5 & 8.7 & 7.0 \\
09-1051D & 95.8 & 90.1 & 68.7 & 58.1 & 37.0 & 24.5 & 16.8 & 12.6 & 10.1 & 8.3 & 6.8 \\
09-1053D & 97.4 & 89.1 & 70.1 & 58.1 & 37.9 & 24.9 & 17.0 & 12.9 & 10.4 & 8.4 & 6.9 \\
09-1056A & 92.7 & 76.4 & 56.6 & 49.9 & 37.5 & 29.0 & 21.7 & 16.2 & 11.6 & 8.5 & 6.3 \\
08-1012E & 100 & 100 & 89.3 & 67.0 & 26.2 & 19.6 & 17.8 & 16.8 & 16.0 & 14.5 & 11.3 \\
08-1025E & 100 & 100 & 90.0 & 63.0 & 25.6 & 19.3 & 17.4 & 16.0 & 14.8 & 13.7 & 11.4 \\
08-1046D & 100 & 99.8 & 83.9 & 61.7 & 23.8 & 14.2 & 11.8 & 10.2 & 8.7 & 7.6 & 5.8 \\
\hline
\end{tabular}


Table 3. Mixture volumetric properties

\begin{tabular}{llllll}
\hline Mix type & Mix ID & $\mathrm{P}_{\mathrm{b}}(\%)$ & AV $(\%)$ & VMA (\%) & VFA(\%) \\
\hline Surface mixes & 08-1019D & 5.4 & 6.8 & 16.6 & 74.5 \\
& 08-1043A & 5.6 & 7.1 & 16.9 & 76.9 \\
08-1045D & 4.4 & 7.8 & 20.3 & 52.5 \\
08-1047D & 5.4 & 6.9 & 15.8 & 76.4 \\
08-1036D & 5.7 & 7.0 & 15.5 & 79.7 \\
08-1052E & 5.9 & 7.1 & 17.2 & 74.9 \\
08-1055D & 5.6 & 7.0 & 16.3 & 74.5 \\
Base mixes & 09-1001E & 5.2 & 6.8 & 17.0 & 70.6 \\
& 08-1044A & 4.5 & 6.9 & 15.0 & 74.1 \\
09-1049A & 4.9 & 7.6 & 14.9 & 71.3 \\
09-1051D & 4.7 & 7.6 & 14.1 & 73.1 \\
Stone matrix asphalt mixes & 09-1053D & 5.0 & 6.0 & 14.1 & 77.8 \\
& 09-1056A & 4.6 & 7.0 & 12.7 & 76.5 \\
& 08-1025E & 6.5 & 7.0 & 18.2 & 88.5 \\
& 08-1046D & 7.1 & 7.5 & 18.2 & 83.2 \\
\hline
\end{tabular}

$\mathrm{Pb}=$ Asphalt content; $\mathrm{AV}=$ air voids; $\mathrm{VMA}=$ voids in mineral aggregate;

$\mathrm{VFA}=$ voids filled with asphalt 
Table 4. Flow number test results

\begin{tabular}{llllll}
\hline Mix type & Mix ID & \multicolumn{3}{l}{ Flow Number $(\mathrm{FN})$} & \multicolumn{2}{l}{ Strain at FN (microstrain) } \\
\cline { 3 - 6 } & & Mean & COV $(\%)$ & Mean & COV $(\%)$ \\
\hline Surface mixes & 08-1019D & 3,373 & 13.2 & 9,180 & 7.0 \\
& 08-1043A & 702 & 23.6 & 11,649 & 20.4 \\
& 08-1045D & 4,385 & 10.5 & 5,809 & 61.7 \\
& 08-1047D & 7438 & 25.5 & 7,214 & 42.0 \\
& 08-1036D & 6,910 & 1.9 & 13,253 & 5.4 \\
& 08-1052E & 5,753 & 24.6 & 11,937 & 1.4 \\
& 08-1055D & 1,133 & 4.6 & 9,627 & 8.0 \\
09-1001E & 8,414 & 17.6 & 7,320 & 26.5 \\
Base mixes & 08-1044A & 2,623 & 38.2 & 15,637 & 13.7 \\
& 09-1049A & 1,624 & 7.9 & 16,627 & 2.6 \\
& 09-1051D & 6,454 & 4.1 & 13,930 & 6.5 \\
& 09-1053D & 6,781 & 9.8 & 11,444 & 13.4 \\
& 09-1056A & 566 & 19.7 & 12,966 & 9.5 \\
Stone matrix asphalt mixes & 08-1012E & 2,810 & 6.0 & 26,586 & 9.5 \\
& 08-1025E & 4,330 & 26.8 & 21,510 & 3.2 \\
& 08-1046D & 1,631 & 27.0 & 10,533 & 6.3 \\
\hline
\end{tabular}


Table 5. Model parameters describing FN as a function of dynamic modulus and gradation

\begin{tabular}{llllll}
\hline Analysis of Variance & & & \\
\hline Source & DF & Sum of squares & Mean square & F Value & Pr $>$ F \\
Model & 10 & 260913334 & 26091333 & 38.33 & $<.0001$ \\
Error & 36 & 24507811 & 680773 & & \\
Corrected Total & 46 & 285421145 & & & \\
& & & & & \\
\hline Variable & Parameter Estimate & Standard Error & Type II SS & F Value & Pr $>$ F \\
\hline & & & & & \\
$\beta_{0}$ & 32498 & 5258.5133 & 26000305 & 38.19 & $<.0001$ \\
$\beta_{1}$ & -2764.1649 & 549.3629 & 17235001 & 25.32 & $<.0001$ \\
$\beta_{2}$ & -196.2659 & 75.5706 & 4591835 & 6.75 & 0.0135 \\
$\beta_{3}$ & 546.6656 & 87.074 & 26832942 & 39.42 & $<.0001$ \\
$\beta_{4}$ & -550.099 & 68.7912 & 43532909 & 63.95 & $<.0001$ \\
$\beta_{5}$ & 484.8973 & 40.0825 & 99630672 & 146.35 & $<.0001$ \\
$\beta_{6}$ & -416.2817 & 44.4777 & 59633772 & 87.6 & $<.0001$ \\
$\beta_{7}$ & -11.2714 & 1.4536 & 40934038 & 60.13 & $<.0001$ \\
$\beta_{8}$ & 31.6091 & 4.3491 & 35961313 & 52.82 & $<.0001$ \\
$\beta_{9}$ & -18.1238 & 3.8087 & 15415436 & 22.64 & $<.0001$ \\
$\beta_{10}$ & -358.5415 & 151.0725 & 3834512 & 5.63 & 0.0231 \\
\hline & & & & &
\end{tabular}


Table 6. Data used for verification of FN as a function of dynamic modulus and gradation (data after Mohammad et al., 2006; Cooper, 2008)

\begin{tabular}{|c|c|c|c|c|c|c|c|c|c|c|c|c|}
\hline \multirow[t]{2}{*}{ Mix ID } & \multicolumn{11}{|c|}{ Sieve size $(\mathrm{mm})$} & \multirow[t]{2}{*}{$\left|\mathrm{E}^{*}\right|(\mathrm{MPa})$} \\
\hline & 25 & 19 & 12.5 & 9.5 & 4.75 & 2.36 & 1.18 & 0.6 & 0.3 & 0.15 & 0.075 & \\
\hline $64 \mathrm{CO}$ & 100 & 98 & 77 & 61 & 41 & 29 & 21 & 15 & 8 & 6 & 4.6 & 248 \\
\hline $70 \mathrm{CO}$ & 100 & 98 & 77 & 61 & 41 & 29 & 21 & 15 & 8 & 6 & 4.6 & 324 \\
\hline $76 \mathrm{CO}$ & 100 & 98 & 77 & 61 & 41 & 29 & 21 & 15 & 8 & 6 & 4.6 & 400 \\
\hline $76 \mathrm{CRM}$ & 100 & 98 & 77 & 61 & 41 & 29 & 21 & 15 & 8 & 6 & 4.6 & 317 \\
\hline 76 RAP 15 & 100 & 95 & 77 & 60 & 37 & 28 & 21 & 16 & 9 & 6 & 4.5 & 241 \\
\hline 64 RAP 40 & 100 & 95 & 77 & 60 & 37 & 28 & 19 & 15 & 9 & 6 & 4.5 & 593 \\
\hline I-10 Vintage & 100 & 100 & 93 & 71 & 30 & 20 & 17 & 15 & 12 & 10 & 8.0 & 600 \\
\hline I-10 Egan BC & 96 & 87 & 68 & 59 & 35 & 23 & 17 & 13 & 7 & 4 & 2.6 & 900 \\
\hline LA 964 BC & 96 & 83 & 65 & 59 & 47 & 35 & 26 & 20 & 11 & 6 & 4.1 & 900 \\
\hline LA $964 \mathrm{WC}$ & 100 & 98 & 83 & 73 & 50 & 35 & 25 & 18 & 12 & 6 & 4.5 & 500 \\
\hline US 190 BC & 97 & 84 & 65 & 59 & 47 & 35 & 26 & 20 & 11 & 6 & 4.1 & 700 \\
\hline I-Egan WC & 100 & 100 & 98 & 89 & 50 & 29 & 19 & 13 & 10 & 8 & 6.5 & 600 \\
\hline
\end{tabular}

$\left|\mathrm{E}^{*}\right|=$ dynamic modulus 


\section{$\underline{\text { List of Figures }}$}

Fig. 1. Dynamic modulus of surface mixes.

Fig. 2. Dynamic modulus of base mixes.

Fig. 3. Dynamic modulus of stone matrix asphalt mixes.

Fig. 4. Flow number test results for a typical asphalt mix.

Fig. 5. Comparison of measured $\mathrm{FN}$ and predicted $\mathrm{FN}$ for the 16 different $\mathrm{AC}$ mixtures tested.

Fig. 6. Comparison of measured and predicted FN for 12 mixtures indicating strong dependence of FN on dynamic modulus and gradation of AC mixtures (measured data after Mohammad et al., 2006 and Cooper, 2008). 
Fig 1

Click here to download high resolution image
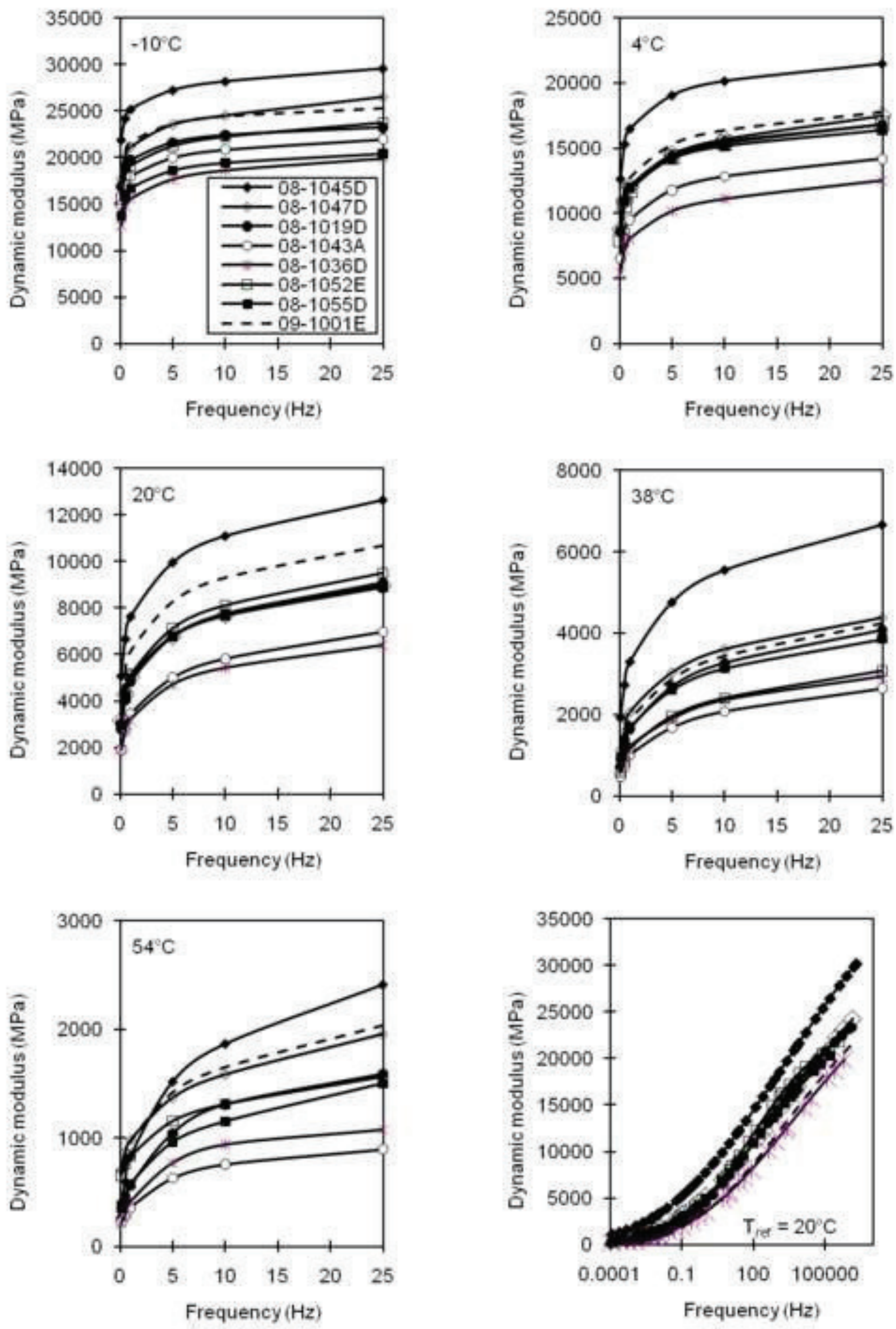
Fig 2

Click here to download high resolution image
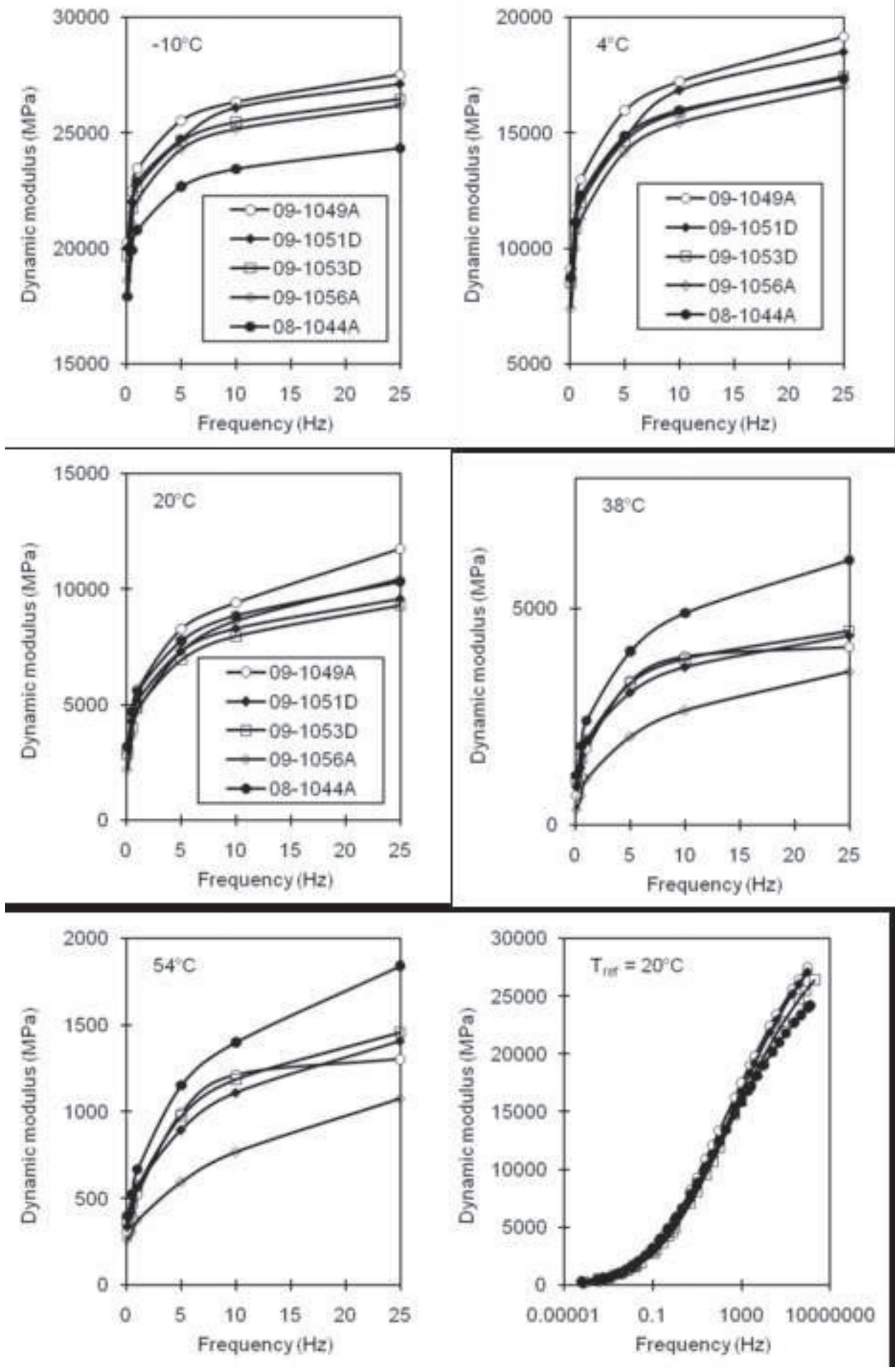
Fig 3

Click here to download high resolution image
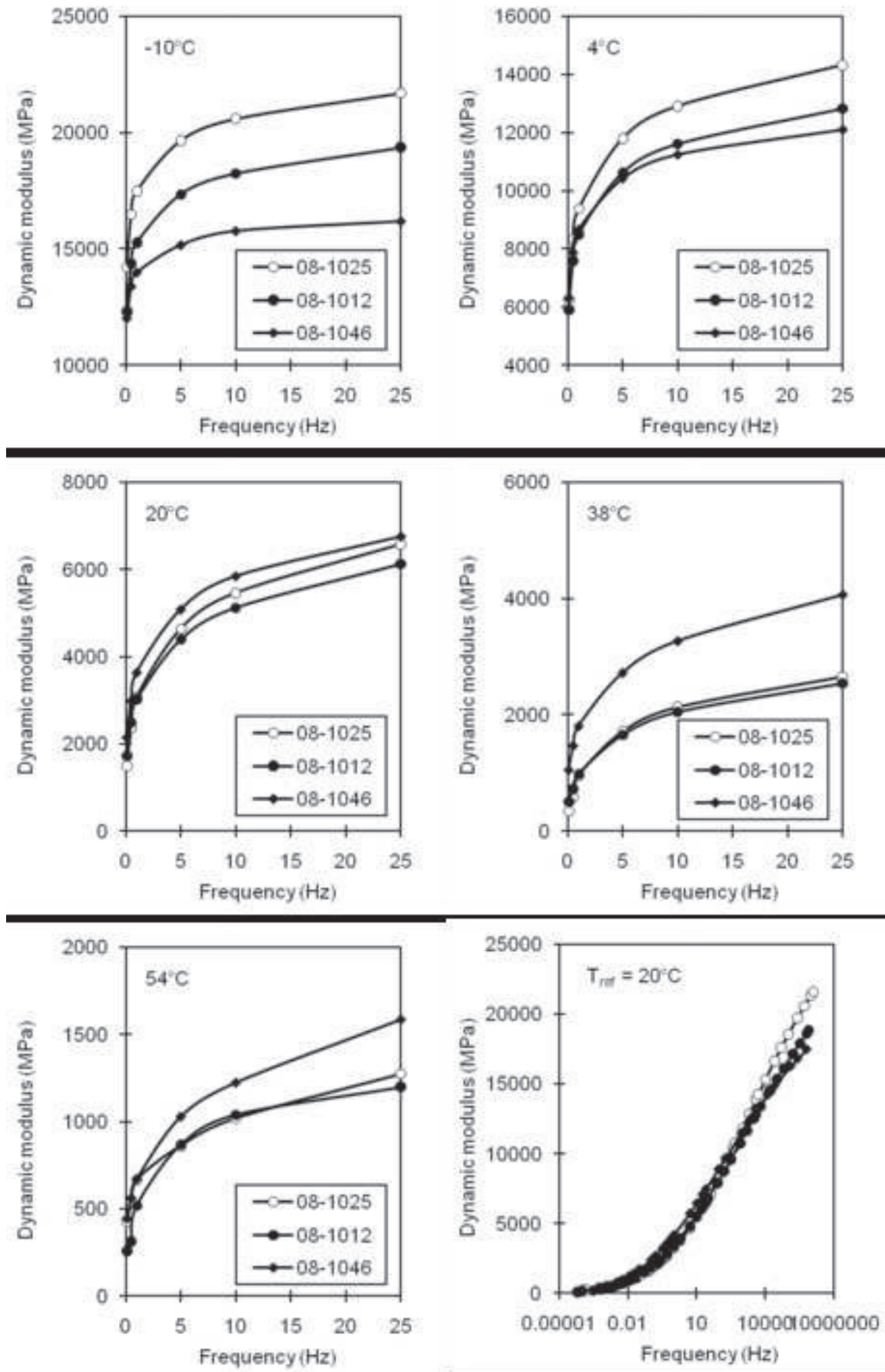
әрК Аә

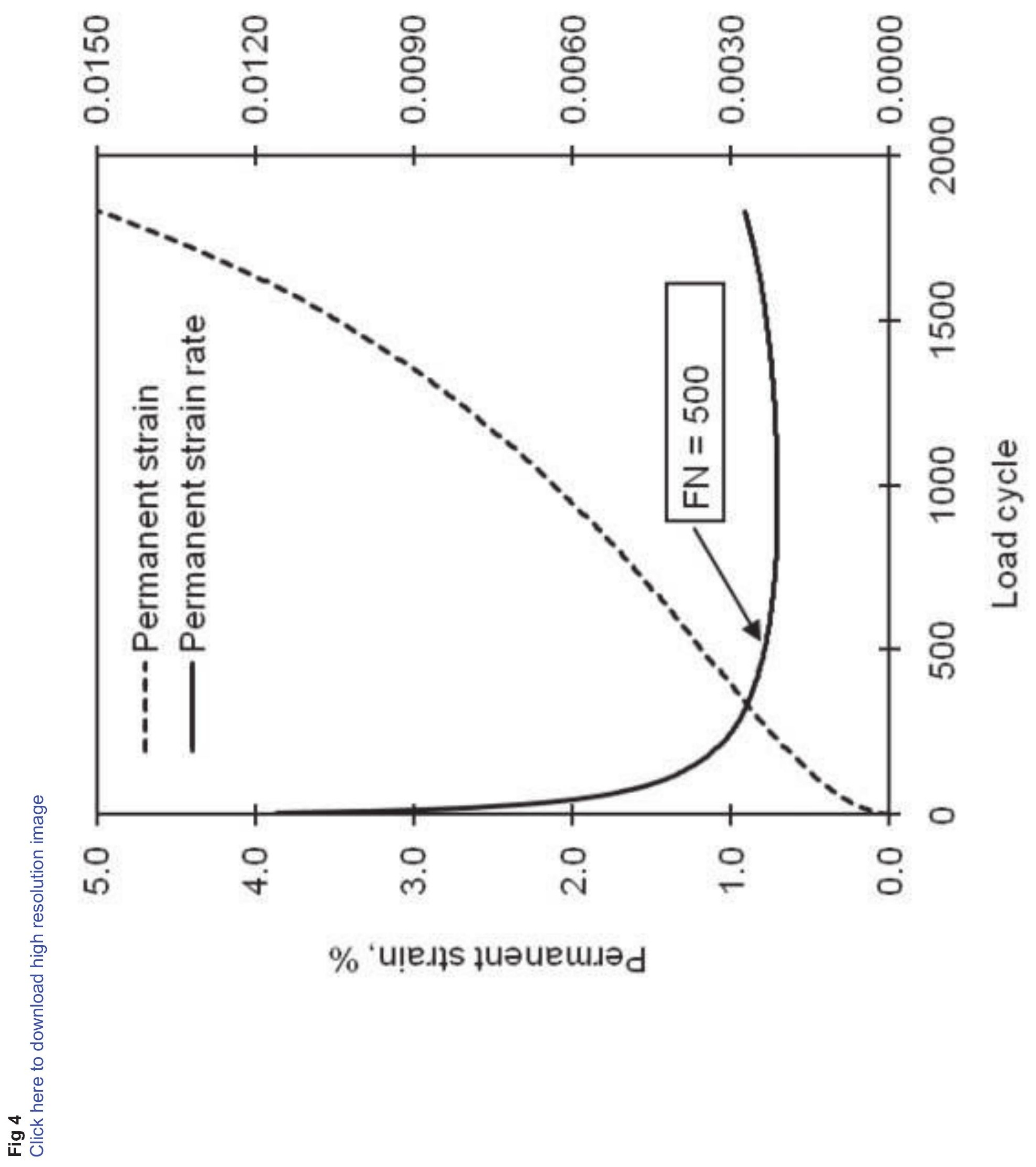




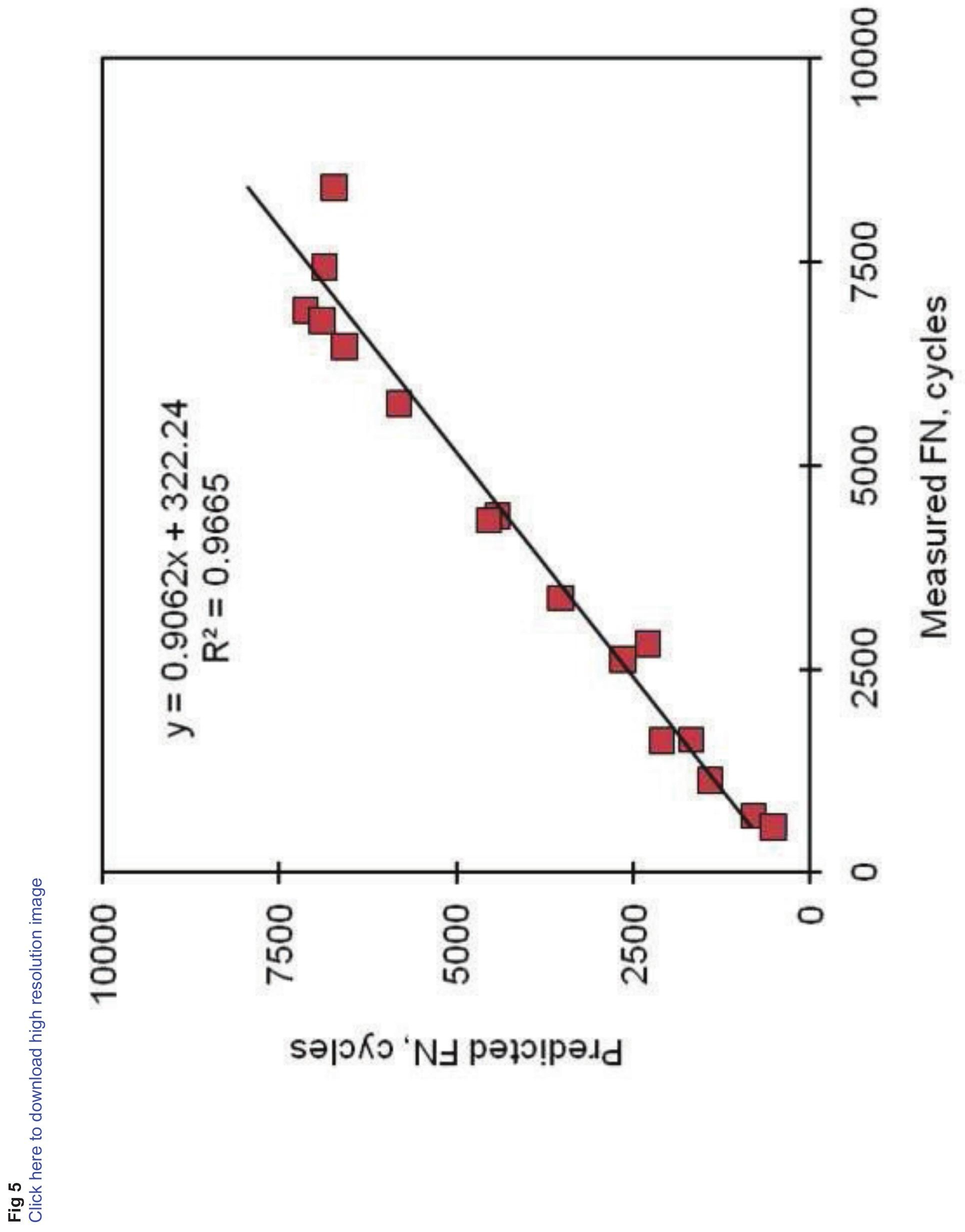




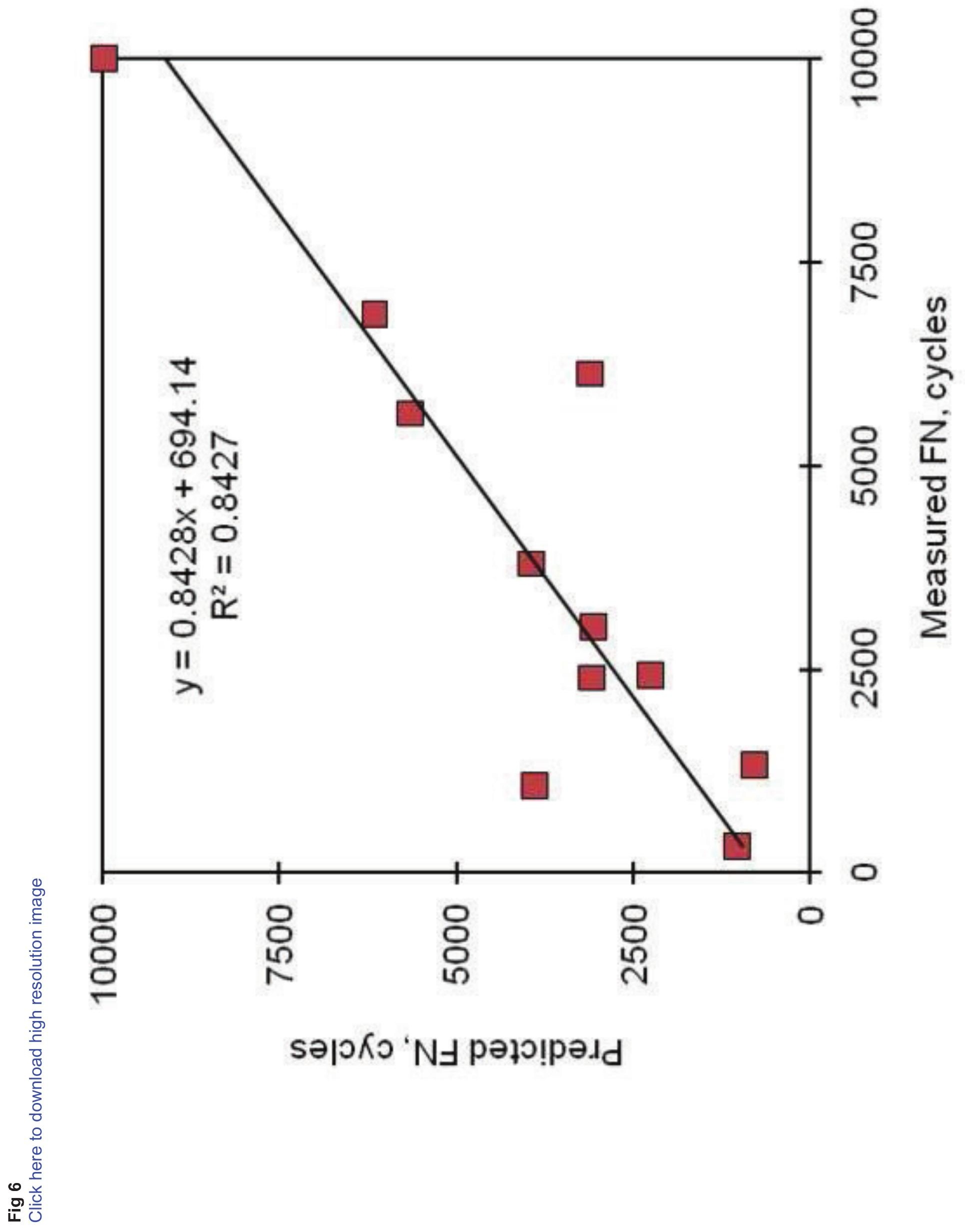

